\title{
THE USEFULNESS OF ADENOSINE DEAMINASE IN THE DIAGNOSIS OF TUBERCULOUS PERICARDITIS
}

\author{
Felipe Francisco TUON(1), Vivian Iida da SILVA(1), Gisele M. Duboc de ALMEIDA(2), Leila ANTONANGELO(2) \& Yeh Li HO(1)
}

\begin{abstract}
SUMMARY
The objective of this study was to evaluate the adenosine deaminase (ADA) activity usefulness in the diagnosis of tuberculous pericarditis (TP), comparing its value with pericardial effusions (PE) caused by other pericardial diseases. A retrospective casecontrol study was conducted with nine cases of TP and 39 other than TP diseases (12 neoplastic, 11 septic and 16 unknown origin). Every patient included in this study had PE samples submitted to ADA activity measures and microbiological analysis, and then had pericardial tissue samples submitted to microbiological and histopathological examination. Considering the value of $40 \mathrm{U} / \mathrm{L}$ as the cut-off for the diagnosis of TP, the specificity and sensitivity were respectively of $72 \%$ and $89 \%$. The specificity of ADA activity for the TP was best applied in the differential diagnosis from PE of unknown origin. The present study demonstrates the clinical value of the measurement of ADA activity in PE in the diagnosis of TP.
\end{abstract}

KEYWORDS: Pericarditis; Tuberculosis; Adenosine deaminase; Acute pericarditis; Pericardial effusion.

\section{INTRODUCTION}

Adenosine deaminase (ADA) is an enzyme present in a great number of plants and animals, found from simple invertebrates to human beings. It is an important enzyme that catalyzes the deamination of adenosine and deoxyadenosine into their respective inosine nucleosides ${ }^{2,10}$. This conversion is an initial step of a series of reactions responsible for lymphocytes proliferation and differentiation. Therefore, ADA is considered an indicator of cellular immunity and fundamental for the differentiation of lymphocytes ${ }^{5}$. In humans, the lack of this enzyme results in severe lymphopenia and immunodeficiency, bringing the risk of an early death for the affected individuals ${ }^{4}$.

ADA is found in several human diseases, lymphocytic effusions, including those consequent of tuberculosis, neoplasm and some acute viral infections. This suggests that a high ADA activity is indirectly related to the subsets of $\mathrm{T}$ cell lymphocytes involved in the inflammatory response $^{18}$.

Macrophages also synthesize ADA, and it is the isoenzyme ADA2 the one produced in greater amount by them. This explains why ADA activity can be high in acute effusions, including that one in which cellular differentiation pattern is predominantly neutrophilic ${ }^{22}$. It is important to remember that ADA is present in all mammalian cells and, despite a number of studies performed to date, the physiological role that it plays in the different tissues is not yet clear ${ }^{8}$.
Tuberculous pericarditis (TP) is a rare form of extrapulmonary tuberculosis frequently associated with high mortality and severe short or long term complications ${ }^{29}$. This is especially true when the diagnosis and the correct treatment of the disease is delayed ${ }^{7}$. Survival time without treatment is approximately four months. Even when the patients receive treatment, the mortality rate ranges from 3 up to $40 \%{ }^{33}$. The main complications of TP are: constrictive pericarditis with or without restrictive hearth failure; cardiac tamponade, a most frequent cause of death if not detected and properly managed ${ }^{12}$. The lack of specificity of TP symptoms makes this condition hard to diagnose ${ }^{7}$. The tuberculin skin test (TST) and thorax radiography are associated with a low positive predictive value of $\mathrm{TP}^{25,30}$. On the other hand, transthoracic echocardiogram is a useful test to detect and quantify pericardial effusion. It is in addition a valuable tool to guide the pericardiocentesis, which can also be performed by videothoracoscopy $y^{23,31}$.

Pericardial effusion (PE) in TP is characterized by a lymphocytic exudate, but occasionally it can be either neutrophilic or mixed ${ }^{26}$. Acid fast bacilli stains on PE sediment are usually negative and culture sensitivity is no greater than $50 \%^{3,6,14}$. Due to the difficulty of establishing the diagnosis of TP using clinical, radiological, cytological or even microbiologic evaluation, attempts to correlate TP diagnosis with other markers have been pursued ${ }^{5}$. The analysis of ADA activity is one of the most studied possibilities and should be highlighted as an accurate measurement method for values greater than $40 \mathrm{U} / \mathrm{L}^{9,17,21,24}$. Unfortunately, as far as we know, there is no knowledge about the 
value of ADA activity in a moderate to high-incidence region of tuberculosis (84-50 per 100,000 pop.).

The objective of this study was to evaluate the ADA activity usefulness in the diagnosis of tuberculous pericarditis, comparing its value in pericardial effusions caused by TP and those caused by other conditions in a moderate to high-incidence region of tuberculosis.

\section{MATERIAL AND METHODS}

A retrospective diagnostic test study was conducted in the Clinical Hospital from Medical School of University of São Paulo. A database search of cases from January 2000 to December 2005 was performed in the Cavity Fluids Laboratory and Clinical Microbiology Laboratory, where all the specimens from pericardial effusions were submitted to ADA activity measurement and microbiological analysis. The histopathological material obtained from these patients was reviewed. Every patient included in the study had PE samples submitted to ADA activity measures and to microbiological analysis, and they also had pericardial tissue samples submitted to microbiological and histopathological examination.

The diagnosis of TP was established when at least one of the following criteria was present: (1) positive culture for Mycobacterium tuberculosis in pericardial tissue or effusion; (2) presence of granulomas containing alcohol-acid resistance bacilli (AFB) in histopathological analysis of pericardium; or (3) presence of granuloma in pericardial tissue associated with active tuberculosis at another site, as previously described criteria ${ }^{7,32,33}$. The control group (non-tuberculous pericardial effusions) was formed with those patients that had pericardial effusions of other etiology. Pericardial effusions were defined as non-tuberculous when the following criteria were fulfilled: no histological evidence of tuberculosis was found, and negative effusion/sputum stain and culture for tuberculosis; or a definite alternative diagnosis was established.

ADA activity (U/L) was determined in every pericardial fluid specimen according to the method described by GIUSTI ${ }^{22}$. The cut-off value for ADA activity considered adequate to presume the diagnosis of TP was established as $40 \mathrm{U} / \mathrm{L}$, as previously determined by several articles about this issue and meta-analysis ${ }^{9,17,21,24,26,32}$.

The cases without microbiological and histopathological examinations were excluded from the analysis.

The pericardial fluid's cytology was analyzed and the total cellularity and percentages of neutrophils and lymphocytes were compared among the different pericardial diseases.

Clinical, histopathological, microbiological and ADA activity information were recorded in Epi Info 6.0 (CDC, Atlanta). The statistical analysis of ADA activity was performed comparing its mean values according to the various PE etiological factors with $t$ Student test. The means $\pm \mathrm{SD}$ (standard deviation) were considered significantly different when a $p$ value $<0.05$ was found. The usefulness of determining ADA activity as a diagnostic tool for TP was evaluated by calculating its sensitivity, specificity, positive predictive value (PPV) and negative predictive value (NPV) expressed as percentage.
Receiver-operating-characteristics (ROC) curve analysis helped to decide the optimal cutoff point for ADA activity (continuous variable) based on their highest diagnostic accuracy. Data were analyzed by using the SPSS statistical package, version 10.0 (SPSS, Inc, Chicago, Illinois).

\section{RESULTS}

Eighty eight cases from 2000 to 2005 in which ADA activity on $\mathrm{PE}$ was measured were identified. From these, 71 specimens were submitted to microbiological analysis. Forty eight specimens were submitted to histopathological evaluation. Eight of these cases had a microbiological test positive for TP (AFB smear or culture positive for $M$. tuberculosis), one case was a granuloma found without positive culture or AFB smear. Since in this case the presence of $M$. tuberculosis was verified in the patient's sputum, the diagnosis of TP was considered positive.

Samples that did not fulfill the diagnostic criteria for TP but were submitted to histopathological examination were selected to form the control group, amounting a total of 39 cases. These included malignant effusions (12 cases), septic pericarditis (11 cases) and some defined as of unknown origin (16 cases).

The patients mean age in the TP group was of 42.5 (25 - 67) years old and $55.5 \%$ of them were male. In the control group the mean age was of $43.8(15-69)$ and $51 \%$ of the patients were male $(p=0.78)$.

The mean ADA activity value in the TP group was of $180.2 \pm 121.9$ and of $47.3 \pm 76.6$ in the control group $(p<0.05)$ (Table 1). Considering the value of $40 \mathrm{U} / \mathrm{L}$ as the cut-off for the diagnosis of TP, the specificity and sensitivity were respectively of $72 \%$ and $89 \%$. When stratified according to the group control diagnosis, the specificity of ADA activity for the tuberculosis diagnosis showed different values (Table 2). ADA activity values were best applied in the differentiation of a TP pericardial effusion and a PE of unknown origin, although without statistical significance. In this group, the specificity was $94 \%$ and the predictive value positive $89 \%$. The positive and negative likelihood ratio (LR+ and LR-) were 3.15 and 0.15 , respectively.

Table 1

ADA activity on pericardial tuberculosis and other causes of pericardial effusion

\begin{tabular}{lcccc}
\hline $\begin{array}{l}\text { Cause of } \\
\text { pericarditis }\end{array}$ & $\mathrm{n}$ & $\begin{array}{c}\text { ADA activity } \\
(\text { mean } \pm \text { SD) }\end{array}$ & CI & $p$ value \\
\hline Tuberculosis & 9 & $180.2 \pm 121.9$ & $(100.9-259)$ & \\
Non Tuberculosis & 39 & $47.3 \pm 76.6$ & $(23.3-71.4)$ & $<0.05$ \\
$\quad$ Neoplasm & 12 & $29.6 \pm 19.9$ & $(18.3-40.4)$ & 0.09 \\
$\quad$ Septic & 11 & $104.2 \pm 128.1$ & $(28.5-179.9)$ & 0.19 \\
$\quad$ Unknown origin & 16 & $21.6 \pm 17.3$ & $(13.1-30.0)$ & 0.08 \\
\hline
\end{tabular}

CI: Confidence interval; SD: Standard deviation.

The levels of ADA activity in neoplasm and bacterial pericarditis are showed on Table 3. Breast and lung cancer were neoplasms with high level of ADA activity, only one case of lymphoma showed increased level of ADA activity from three cases. There was association 
Table 2

Comparison of tuberculous pericarditis effusion ADA activity and other diagnosis

\begin{tabular}{|c|c|c|c|c|c|c|c|c|}
\hline & Total & $\begin{array}{c}\mathrm{ADA} \\
>40\end{array}$ & $\begin{array}{c}\text { ADA } \\
<40\end{array}$ & Sens & Spec & PPV & NPV & Accuracy \\
\hline Tuberculosis & 9 & 8 & 1 & & & & & \\
\hline Non tuberculosis & 39 & 11 & 28 & & & & & \\
\hline Total & 48 & 19 & 39 & 89 & 72 & 42 & 96 & 75 \\
\hline Tuberculosis & 9 & 8 & 1 & & & & & \\
\hline Neoplasia & 12 & 3 & 9 & & & & & \\
\hline Total & 21 & 11 & 10 & 89 & 75 & 73 & 90 & 81 \\
\hline Tuberculosis & 9 & 8 & 1 & & & & & \\
\hline Septic & 11 & 7 & 4 & & & & & \\
\hline Total & 20 & 15 & 5 & 89 & 36 & 53 & 80 & 60 \\
\hline Tuberculosis & 9 & 8 & 1 & & & & & \\
\hline Unknown origin & 16 & 1 & 15 & & & & & \\
\hline Total & 25 & 9 & 16 & 89 & 94 & 89 & 94 & 92 \\
\hline
\end{tabular}

Sens: Sensitivity; Spec: Specificity; PPV: Positive predictive value; NPV: Negative predictive value.

Table 3

Values of ADA activity and correspondent neoplasm or etiologic agent in septic pericarditis

\begin{tabular}{llll}
\hline $\begin{array}{l}\text { ADA Value } \\
(\mathrm{U} / \mathrm{L})\end{array}$ & Primary neoplasm & $\begin{array}{l}\text { ADA value } \\
(\mathrm{U} / \mathrm{L})\end{array}$ & Etiology of septic pericarditis \\
\hline 22.9 & Lung & 332 & H. influenzae \\
62.5 & Breast & 77.8 & Gram positive coccus on tissue \\
34.9 & Lymphoma & 47.9 & Staphylococcus sp. \\
56.8 & Lymphoma & 27 & Staphylococcus sp. \\
33.5 & Neuroendocrine & 5.6 & Staphylococcus aureus \\
10.8 & Lung & 147 & Acinetobacter baumannii \\
59.1 & Lung & 9.6 & Pseudomonas aeruginosa \\
17 & Lung & 3.5 & Staphylococcus sp. \\
14.7 & Lymphomas & Staphylococcus aureus \\
12.6 & Adamantinoma & 54 & Gram negative bacillus \\
7.1 & Metastatic unknown & 76 & \\
23 & Lung & 366 &
\end{tabular}

between etiological agent and ADA activity levels. The cytological analysis of TP samples showed a neutrophilic predominance and there was a significant difference when compared to PE of unknown origin or neoplastic PE. There was no difference between bacterial pericarditis and TP when comparing the cytological study. The pericardial fluid cellularity was not defined as characteristic of any of the diseases (Table 4). The area under curve (AUC) of ROC analysis was of 0.85 (Fig. 1). This is a satisfying number and it permitted the calculation of the ideal ADA activity cut-off value in the diagnosis of TP. The ideal cutoff of our study was $39.95 \mathrm{U} / \mathrm{L}$.

\section{DISCUSSION}

Tuberculous pericarditis is a rare clinical condition in developed countries. On the other hand, the number of TP cases in developing countries is underestimated due to difficulties in the diagnosis, which require high cost procedures and laboratorial exams not readily available in most of health services. In these countries, TP is the leading cause of PE among pericardial diseases, responsible for more than $70 \%$ of the cases $^{26}$.

Our study confirmed typical aspects of ADA activity in the TP, the results being consistent with the data found in the literature ${ }^{9}$. The mean value of ADA activity in TP pericardial effusions was significantly higher than in those caused by non-tuberculous pericarditis. However, this difference was not sustained when comparing each specific cause of pericarditis, since the number of patients in the various groups was limited. The ideal number of TP cases for the study's statistical analysis was determined calculating the sample size. This sample estimative took into consideration errors type I and II and the minimal number of 


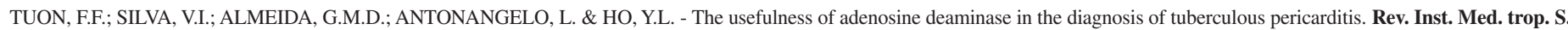
Paulo, 49(3): 165-170, 2007.

Table 4

Cytology of various pericarditis and comparison with tuberculous pericarditis

\begin{tabular}{|c|c|c|c|c|c|}
\hline Cause of pericarditis & $\mathrm{n}$ & $\begin{array}{c}\text { Total cellularity } \\
\text { (Mean of cell } / \mathrm{mL})\end{array}$ & $\begin{array}{c}\mathrm{N} \\
(\% \pm \mathrm{SD})\end{array}$ & $\begin{array}{c}\mathrm{L} \\
(\% \pm \mathrm{SD})\end{array}$ & $p$ value \\
\hline Tuberculosis & 9 & 2210 & $81 \pm 18$ & $18 \pm 19$ & \\
\hline Non Tuberculosis & 39 & 2738.9 & $36 \pm 33$ & $63 \pm 33$ & $<0.05$ \\
\hline Neoplasm & 12 & 2805.8 & $19 \pm 16$ & $80 \pm 22$ & $<0.05$ \\
\hline Septic & 11 & 5347.7 & $59 \pm 37$ & $39 \pm 37$ & 0.19 \\
\hline Unknown origin & 16 & 707.6 & $30 \pm 31$ & $55 \pm 31$ & $<0.05$ \\
\hline
\end{tabular}

N: Neutrophils; L: Lymphocytes.

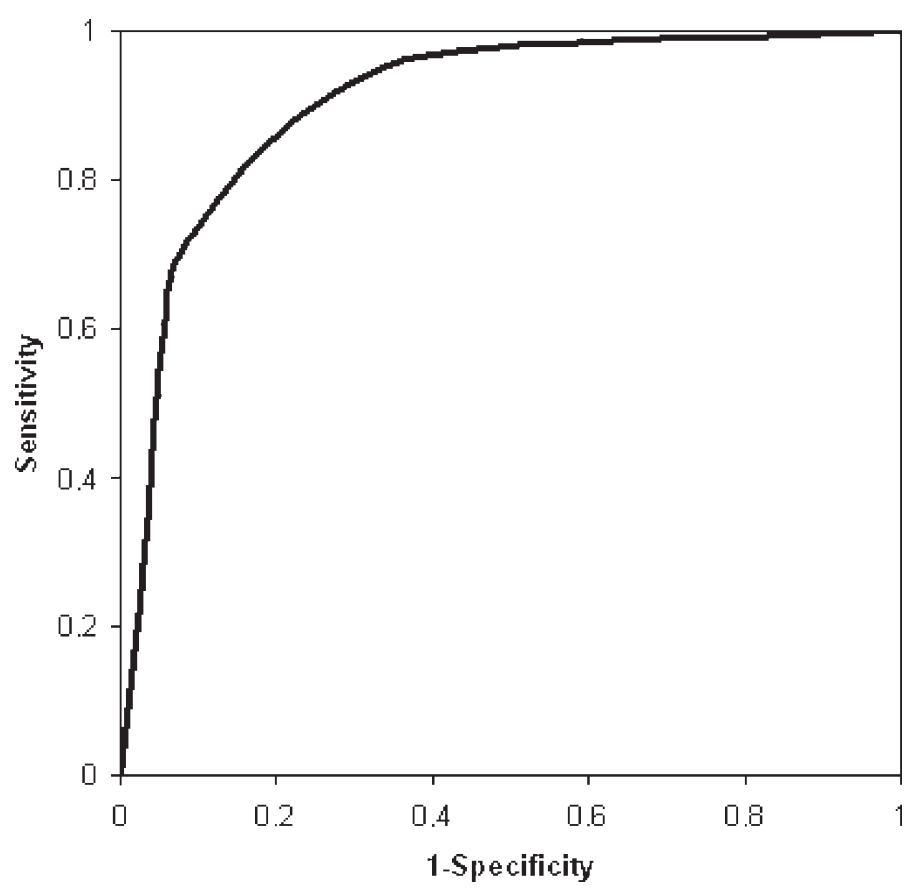

Fig. 1 - Curve ROC graph for ADA activity in pericardial effusion to diagnosis of tuberculous pericarditis.

cases found to be necessary was eight ${ }^{15}$. The ideal number of control cases was three times bigger. Since the number of identified TP cases was nine and the total number of non-tuberculous pericarditis was of 33 cases, the proportion was satisfactory. Nevertheless, the comparison of the different subtypes of pericarditis could not be properly assessed with these numbers. Furthermore, calculating the mean value of ADA activity was not the best approach to evaluate the true significance of this laboratory assay due to total number of cases in each etiology.

The ADA activity sensitivity for TP in our study was similar to that found in other studies ${ }^{9,17,21,24,25}$. Only recently, a meta-analysis evaluating ADA activity levels in TP obtained a mean sensitivity of $88 \%$ (CI $82-91 \%)^{32}$. Therefore, the result of $89 \%$ that we originated indicates that measuring ADA activity in PE is, indeed, useful as a screening investigation for TP.
The same conclusion cannot be reached when analyzing the specificity value we verified, which was of $72 \%$. This result was higher in PE of unknown origin and lower in septic PE. It was a surprise to find such a high level of ADA activity in septic PE, similar to the numbers ascribed to TP. It is true that this pattern has been observed in other studies ${ }^{9,17,25}$, but the number of septic pericarditis cases they brought to attention was always limited and did not weight in the calculus of their control groups' mean ADA activity. The cellularity analysis of the PE samples showed the same pattern in TP and septic PE, a neutrophilic predominance. This aspect of our study has not been previously reported in reference to TP. In truth, every study up until now associates a lymphocytic predominance with the condition.

This test will not confirm with certainty the TP diagnosis, rather it corroborates to the diagnosis substantially, independent of the predictive pre-test values, which was not evaluated. For this reason we calculated the LR+ and LR-. With these values, the clinician can associate a pretest probability with ADA activity and verify how much the ADA activity results could rise the probability of $\mathrm{TP}^{11}$. The opposite is also true, since the specificity of ADA activity was high. Although ADA activity could be used as a sole method of diagnosis, cultures should be available due to the increasing incidence of multidrug resistant tuberculosis ${ }^{27}$.

The difficulty to establish the etiologic diagnosis of TP fosters the search of a reliable, quick and affordable diagnostic test for this illness. Several studies have demonstrated the importance of the cytological pattern, nucleic acid amplification (NAA), lysozyme and $\gamma$-interferon among others, but the most studied factor so far is the ADA activity ${ }^{1,21,24}$. Despite the existence of some studies concerning ADA activity and TP, few publications have yet compared ADA activity in TP and septic pericarditis. In Brazil, FRODE \& MEDEIROS, using an animal model of pleurisy, demonstrated the increased level of ADA activity in early inflammation and its coincidence with the neutrophils raise ${ }^{13}$. In addition, other studies have demonstrated that high levels of ADA activity can be found in neutrophilic effusions, including those caused by tuberculosis ${ }^{16,19}$. Further studies on the microenvironment of pericardium and inflammation are needed to explain this finding.

In our study, the neoplasm cases did not have significantly increased levels of ADA activity, not even when analyzing its specific subgroups. The values of sensitivity and specificity were acceptable. 
The study's ideal cut-off, calculated using the AUC of ROC curve, was identical to the one used in the literature. This value allows, with a reasonable accuracy, the establishment of the diagnosis of TP.

The present study was able to demonstrate that ADA activity has a high sensitivity for TP, and thus prove that it is a useful tool to achieve this diagnosis. Nonetheless, it is not a reliable method to differentiate TP and septic pericarditis. Hence it substantially corroborates for the TP diagnosis, independently of predictive pretest values, when septic pericarditis is not a possibility. Given that the cut-off of $40 \mathrm{U} / \mathrm{L}$ can be used with security and the sensitivity values found in our study were high, we conclude that it is feasible to use ADA activity measures to diagnose TP. Moreover, when septic pericarditis is excluded, it can guide physicians in starting antituberculous treatment. In contrast, the specificity we found was not so high, not helping in the exclusion of the diagnosis when patients present with normal values of ADA activity.

When the test is applied in populations with high prevalence of the disease, the positive predictive value increases due to lower proportion of false-positive results. Therefore, a increased ADA level in a PE of patient living in a country with high prevalence of TP (developing countries) will be more reliable than one performed in a developed country. In countries with low prevalence of TP, a decreased ADA level will be more reliable than an increased level, because the number of true-negative is high. The positive predictive value increases and decreases in accordance with the prevalence of the target condition in the screened population. Thus, unlike sensitivity and specificity, the positive predictive value is not a constant performance characteristic of a screening test. If the target condition is sufficiently rare in the screened population, even tests with excellent sensitivity and specificity can have low positive predictive value, generating more false-positive than true-positive results ${ }^{20}$.

Adenosine deaminase activity is a cost-effective test in the diagnosis of pleural tuberculosis. Cost-effectivity study should be performed in this group of patients with TP, and probably it will show a similar result, once the sensitivity and specificity are coincident ${ }^{28}$.

In summary, the present study demonstrates the clinical value of measurement of ADA activity in PE, a simple and affordable test in a population of moderate to high-incidence region of tuberculosis in the diagnosis of pericardial tuberculosis.

\section{RESUMO}

\section{O uso da adenosina deaminase no diagnóstico da tuberculose pericárdica}

O objetivo deste estudo foi avaliar a atividade da adenosina deaminase (ADA) como auxiliar no diagnóstico da tuberculose pericárdica (TP), comparando o seu valor no derrame pericárdico com outras doenças pericárdicas. Um estudo retrospectivo tipo caso-controle foi conduzido com nove casos de TP e 39 pacientes com outras doenças pericárdicas (12 neoplasias, 11 pericardites bacterianas e 16 pericardites de etiologia indeterminada). Cada paciente incluído no estudo teve sua amostra de tecido pericárdico encaminhada para estudo microbiológico e histopatológico. Considerando o valor de $40 \mathrm{U} / \mathrm{L}$ como corte para o diagnóstico de TP, a especificidade e sensibilidade foram respectivamente 72 e $89 \%$. A especificidade da atividade de ADA para a TP foi melhor aplicada no diagnóstico diferencial entre derrame pericárdico de origem indeterminada. O presente estudo demonstrou o valor clínico da mensuração da atividade de ADA no diagnóstico de TP.

\section{REFERENCES}

1. AGGELI, C.; PITSAVOS, C.; BRILI, S. et al. - Relevance of adenosine deaminase and lysozyme measurements in the diagnosis of tuberculous pericarditis. Cardiology, 94: 81-85, 2000.

2. AKALAL, D.B.; SCHEIN, C.H. \& NAGLE, G.T. - Mollusk-derived growth factor and the new subfamily of adenosine deaminase-related growth factors. Curr. pharmaceut. Des., 10: 3893-3900, 2004.

3. BECIT, N.; UNLU, Y.; CEVIZ, M. et al. - Subxiphoid pericardiostomy in the management of pericardial effusions: case series analysis of 368 patients. Heart, 91: 785-790, 2005.

4. BLACKBURN, M.R. \& KELLEMS, R.E. - Adenosine deaminase deficiency: metabolic basis of immune deficiency and pulmonary inflammation. Advanc. Immunol., 86: $1-41,2005$.

5. BLAKE, J. \& BERMAN, P. - The use of adenosine deaminase assays in the diagnosis of tuberculosis. S. Afr. med. J., 62: 19-21, 1982.

6. CEGIELSKI, J.P.; DEVLIN, B.H.; MORRIS, A.J. et al. - Comparison of PCR, culture, and histopathology for diagnosis of tuberculous pericarditis. J. clin. Microbiol., 35 3254-3257, 1997.

7. CHERIAN, G. - Diagnosis of tuberculous aetiology in pericardial effusions. Postgrad. med. J., 80: 262-266, 2004.

8. CRISTAlLI, G.; COSTANZI, S.; LAMBERTUCCI, C. et al. - Adenosine deaminase: functional implications and different classes of inhibitors. Med. Res. Rev., 21: 105$128,2001$.

9. DOGAN, R.; DEMIRCIN, M.; SARIGUL, A.; CILIV, G. \& BOZER, A.Y. - Diagnostic value of adenosine deaminase activity in pericardial fluids. J. cardiovasc. Surg., 40: 501-504, 1999.

10. DOLEZELOVA, E.; ZUROVEC, M.; DOLEZAL, T.; SIMEK, P. \& BRYANT, P. J. - The emerging role of adenosine deaminases in insects. Insect Biochem. molec. Biol., 35: 381-389, 2005.

11. FAGAN, T.J. - Normograma for Bayes theorem. New Engl. J. Med., 293: 257, 1975.

12. FOWLER, N.O. - Tuberculous pericarditis. J. Amer. med. Ass., 266: 99-103, 1991.

13. FRODE, T.S. \& MEDEIROS, Y.S. - Myeloperoxidase and adenosine-deaminase levels in the pleural fluid leakage induced by carrageenan in the mouse model of pleurisy. Mediators Inflamm., 10: 223-227, 2001

14. HAKIM, J.G.; TERNOUTH, I.; MUSHANGI, E. et al. - Double blind randomised placebo controlled trial of adjunctive prednisolone in the treatment of effusive tuberculous pericarditis in HIV seropositive patients. Heart, 84: 183-188, 2000.

15. HUHN, M. \& PIEPHO, H.P. - Determining the sample size for co-dominant molecular marker-assisted linkage detection for a monogenic qualitative trait by controlling the type-I and type-II errors in a segregating F2 population. Theoret. appl. Genet., 106: $840-845,2003$

16. IKEDA, T.; IKEDA, N.; KURASAWA, T. et al. - A case of tuberculous infection of emphysematous bulla in the superior segment of left lower lobe. Kekkaku, 71: 619623, 1996. 


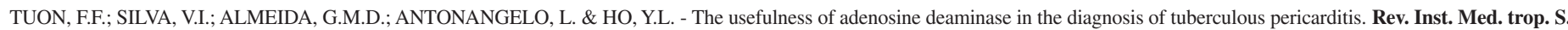
Paulo, 49(3): 165-170, 2007.

17. KOH, K.K.; IN, H.H. LEE, K.H. et al. - New scoring system using tumor markers in diagnosing patients with moderate pericardial effusions. Int. J. Cardiol., 61: 5-13, 1997.

18. KOMSUOGLU, B.; GOLDELI, O.; KULAN, K. \& KOMSUOGLU, S.S. - The diagnostic and prognostic value of adenosine deaminase in tuberculous pericarditis. Europ. Heart J., 16: 1126-1130, 1995.

19. KOSE, K.; YAZICI, C. \& ASSIOGLU, O. - The evaluation of lipid peroxidation and adenosine deaminase activity in patients with Behcet's disease. Clin. Biochem., 34: 125-129, 2001

20. LANIADO-LABORIN, R. - Adenosine deaminase in the diagnosis of tuberculous pleural effusion: is it really an ideal test? A word of caution. Chest, 127: 417-418, 2005.

21. LEE, J.H.; LEE, C.W.; LEE, S. et al. - Comparison of polymerase chain reaction with adenosine deaminase activity in pericardial fluid for the diagnosis of tuberculous pericarditis. Amer. J. Med., 113: 519-521, 2002.

22. LETIEXHE, M.; PIERARD, L. \& KULBERTUS, H. - Tuberculous pericarditis: value of adenosine deaminase activity level assessment. Rev. méd. Liege, 47: 502-509, 1992.

23. LIU, P.Y.; LI, Y.H.; TSAI, W.C. et al. - Usefulness of echocardiographic intrapericardial abnormalities in the diagnosis of tuberculous pericardial effusion. Amer. J. Cardiol., 87: 1133-1135, 2001

24. MARTINEZ-VAZQUEZ, J.M.; RIBERA E.; OCANA, I. et al. - Adenosine deaminase activity in tuberculous pericarditis. Thorax, 41: 888-889, 1986.

25. REUTER, H.; BURGESS, L.J. \& DOUBELL, A.F. - The role of chest radiography in diagnosing patients with tuberculous pericarditis. Cardiovasc. J. S. Afr., 16: 108$111,2005$.
26. REUTER, H.; BURGESS, L.J.; CARSTENS, M.E. \& DOUBELL, A.F. - Adenosine deaminase activity - more than a diagnostic tool in tuberculous pericarditis. Cardiovasc. J. S. Afr., 16: 143-147, 2005.

27. SHARMA, S.K. \& MOHAN, A. - Multidrug-resistant tuberculosis. Indian J. med. Res., 120: 354-376, 2004.

28. SHARMA, S.K. \& BANGA, A. - A. Pleural fluid interferon-gamma and adenosine deaminase levels in tuberculosis pleural effusion: a cost-effectiveness analysis. J. clin. Lab. Anal., 19: 40-46, 2005.

29. TRAUTNER, B.W. \& DAROUICHE, R.O. - Tuberculous pericarditis: optimal diagnosis and management. Clin. infect. Dis., 33: 954-961, 2001.

30. TUON, F.F. - Tuberculin skin test and tuberculous pericardial effusions. In: CHERIAN G. Diagnosis of tuberculous aetiology in pericardial effusions. Postgrad. med. J., 80: 262-266, 2004. e- letters: http://pmj.bmjjournals.com/cgi/eletters /80/943/ 262 ?ck $=$ nck

31. TUON, F.F.; LITVOC, M.N. \& LOPES, M.I. - Adenosine deaminase and tuberculous pericarditis. A systematic review with meta-analysis. Acta trop., 99: 67-74, 2006.

32. TUON, F.F. - Video-assisted thoracoscopy and tuberculous pericarditis. Ann. thorac. Surg., 81: 2338, 2006.

33. YANG, C.C.; LEE, M.H.; LIU, J.W. \& LEU, H.S. - Diagnosis of tuberculous pericarditis and treatment without corticosteroid in a tertiary teacher hospital in Taiwan: a-14 years experience. J. Microbiol. Immunol. Infect., 38: 47-52, 2005.

Received: 18 July 2006

Accepted: 26 October 2006 